\title{
Perfil de propriedades leiteiras de Santa Catarina em relação à Instrução Normativa 51
}

\author{
Profile of dairy farms in Santa Catarina State in relation to Normative Instruction 51
}

\author{
WINCK, César Augustus ${ }^{1 *}$; THALER NETO, André ${ }^{2}$
}

\author{
${ }^{1}$ Universidade do Oeste de Santa Catarina, Campus de Joaçaba, Departamento de Agronomia, Campos \\ Novos, Santa Catarina, Brasil. \\ ${ }^{2}$ Universidade do Estado de Santa Catarina, Centro de Ciências Agroveterinárias, Departamento de \\ Produção Animal e Alimentos, Lages, Santa Catarina, Brasil. \\ *Endereço para correspondência: cesar.cepan@gmail.com
}

\section{RESUMO}

Santa Catarina é o quinto maior produtor de leite do país, sendo essa atividade uma importante fonte de renda para os produtores. Para a continuidade dessa realidade, torna-se importante que atendam às normas de qualidade do leite estabelecidas pela Instrução Normativa 51/2002 (IN 51). Com o objetivo de identificar o perfil de propriedades leiteiras e verificar a percepção dos produtores sobre as exigências de qualidade do leite estabelecidas pela IN 51, realizou-se uma pesquisa diagnóstica por meio da aplicação de questionário, estruturado a 166 produtores de leite das regiões catarinenses do Meio-oeste e Alto Vale do Itajaí, no período de abril a setembro de 2006. As propriedades apresentavam, em sua maioria, perfil compatível com a agricultura familiar, isto é, comercializavam em média 97,6kg de leite/dia, com 13,6 vacas em lactação, por terreno. Os produtores apresentavam baixo nível de escolaridade e idade superior 40 anos. O leite era uma das duas principais atividades econômicas em $88,0 \%$ das propriedades. Uma parcela considerável desses produtores ainda realizava ordenha manual $(33,7 \%)$ em estábulo convencional $(94 \%)$ e conservava o leite em imersão em água gelada (56,6\%). Menos de 30\% conheciam a IN 51, e a maioria considerava que a IN 51 teria alto impacto em suas propriedades, independente do nível de produção de leite. Na opinião dos produtores, para cumprirem os requisitos mínimos de qualidade do leite previstos, há a necessidade de adquirir equipamentos, mas dar ênfase à melhoria da higiene de ordenha e do controle da mastite não era considerada uma missão indispensável.

Palavras-chave: agricultura familiar, fatores socioeconômicos, qualidade do leite

\section{SUMMARY}

Santa Catarina is the fifth largest milk producer in Brazil, and milk production is an important source of income for farmers. For the continuity of this reality, it is important that farmers be suited to the milk quality standards set by Normative Instruction 51/2002 (IN 51). With the objective to identify the profile of dairy farms and to verify the perception of farmers on milk quality requirements set by IN 51, a diagnostic research was carried out through the application of a structured questionnaire to 166 dairy farmers in the regions of Meio-oeste and Alto Vale do Itajaí, in the period among April to September 2006. The farms presented mostly, profile compatible with familiar agriculture, selling an average of $97.6 \mathrm{~kg}$ of milk/day, with an average of 13.6 cows in lactation per farm. Farmers had a low education level and age over 40 years. Milk was one of two main economical activities in $88.0 \%$ of farms. Considerable portion of the farmers still performs manual milking (33.7\%) in conventional stall (94\%) and kept the milk in bulk tank $(56.6 \%)$. Less than $30 \%$ of the farmers knew the IN 51, and among these, the majority believes that the IN 51 will have high impact on their farms, which is not related to the level of milk production. In the opinion of the farmers, to adapt to IN 51, they need to acquire equipments, but in their opinion it is not necessary, to emphasizes on hygiene and milking control of mastitis.

Keywords: familiar agriculture, milk quality, socioeconomic factors 


\section{INTRODUÇ̃̃̃O}

A cadeia produtiva do leite possui grande importância na economia brasileira. Destacou-se na última década pelo rápido crescimento produtivo e econômico (FIGUEIREDO\& PAULILLO, 2006), o que permitiu que o país ganhasse posição de destaque no comércio internacional de leite e derivados (SIQUEIRA et al., 2010).

A atividade possui notoriedade em Santa Catarina, quinto maior produtor de leite fluído do país, com $8,02 \%$ da produção nacional em 2010 (ZOCCAL, 2011). Destacam-se nesse cenário o intenso crescimento da atividade, com taxa média anual de 8,8\% entre 2003 e 2007 , bem como a produção baseada na agricultura familiar, visto que as propriedades possuem, na sua maioria, áreas de até 50 hectares e respondem por aproximadamente $83 \%$ da produção de leite (ICEPA, 2011). A atividade leiteira é economicamente importante em pequenas propriedades (até 15 hectares). Em muitas propriedades, a produção de leite se configura como primeira atividade de maior geração de renda $(60 \%)$, ou, de segunda $(50 \%)$ (MARCONDES, 2005).

No ano de 2002, as normas brasileiras que tratam da qualidade do leite e seus derivados passaram por um processo de atualização, o que acarretou a adequação destas às exigências de qualidade do mercado interno e externo. Essa atualização aconteceu por meio da Instrução Normativa 51 (IN 51), editada pelo Ministério da Agricultura, Pecuária e Abastecimento (BRASIL, 2002), cujo objetivo foi melhorar a qualidade do leite cru produzido no país.

A IN 51 estabeleceu novos desafios aos produtores, ao estabelecer parâmetros mínimos de qualidade do leite para as propriedades e como meta fundamental para a permanência do produtor na atividade (WINCK \& THALER NETO, 2009). Além disso, observa-se atualmente a tendência de implantação de sistemas de pagamento por qualidade no país, com base em teores de sólidos do leite, Contagem Bacteriana Total (CBT) e Contagem de Células Somáticas (CCS), dentre outros indicadores (ROMA et al., 2009). Dessa forma, a obtenção de elevados níveis de qualidade poderá ser fundamental para viabilizar a atividade leite (NERO et al., 2009), especialmente na pequena propriedade (BODENMÜLLER FILHO et al., 2010) mais vulnerável à flutuação de preços (SIQUEIRA et al., 2010).

Neste trabalho objetivou-se avaliar o perfil socioeconômico e cultural dos produtores de leite, suas percepções sobre as exigências de qualidade do leite estabelecidas pela IN 51, o rebanho e a infra-estrutura para ordenha e conservação do leite, em propriedades rurais de duas regiões de Santa Catarina.

\section{MATERIAL E MÉTODOS}

O estudo foi realizado nas regiões do Meio-oeste e Alto Vale do Itajaí do Estado de Santa Catarina, que correspondem juntas a 20,0\% do território e a $23,8 \%$ da produção de leite no Estado, porcentagem que já representou 505,9 milhões de litros em 2010 (ICEPA, 2011). Realizou-se a aplicação de um questionário estruturado a 166 produtores de leite, fornecedores de duas das principais indústrias de laticínios com abrangência naquelas regiões, que atingiram 28 municípios (40,5\% das duas regiões), no período de abril a setembro de 2006, seguindo metodologia descrita por Haguette (1990) e Thiollent (1996). A amostra de propriedades correspondeu a aproximadamente $11 \%$ das propriedades 
que fornecem leite às indústrias de laticínios participantes da pesquisa.

$\mathrm{O}$ questionário envolvia informações socioeconômicas e culturais dos produtores de leite, sobre o rebanho e a atividade leiteira, instalações e equipamentos para ordenha/conservação do leite e conhecimento e percepção do produtor em relação às exigências da Instrução Normativa 51 (BRASIL, 2002). Para a seleção dos produtores, os mesmos foram ordenados por volume de leite comercializado no mês de início do experimento. $\mathrm{O}$ estabelecimento desse critério implicou a eliminação de produtores com menos de 10 litros por dia ou com sistema de tanques comunitários da pesquisa. A partir da base de dados ordenada, excluíam-se oito produtores, selecionando o produtor seguinte. Essa etapa foi repetida do maior ao menor produtor e almejava obter uma amostra proporcional em relação ao volume de leite comercializado.

Os resultados da aplicação dos questionários foram processados pelo programa SPHINX LÉXICA, pacote estatístico para análise de resultados de entrevistas e estudos quantitativos e qualitativos. As análises estatísticas foram realizadas utilizando-se os programas estatísticos SPHINX LÉXICA ${ }^{\circledR}$ e SAS $^{\circledR}$.

As variáveis qualitativas e a relação destas com o perfil dos produtores e propriedades leiteiras foram analisadas através de teste de $\chi^{2}$ (Qui-quadrado). Para variáveis dependentes quantitativas, os dados foram submetidos à análise de variância, sendo previamente testados para normalidade dos resíduos pelo teste de Shapiro-Wilk, e as médias comparadas pelo Teste de Tukey, ao nível de 5\% de significância.

\section{RESULTADOS E DISCUSSÃO}

Os dados obtidos a partir das entrevistas permitiram traçar um perfil socioeconômico e cultural dos produtores de leite. $\mathrm{Na}$ maioria das propriedades $(86,1 \%)$, os responsáveis pela produção de leite eram os próprios proprietários (as) e suas esposas(os), geralmente casados $(87,3 \%)$, com idade acima de 40 anos $(66,2 \%)$ e com baixo nível de escolaridade $(68,7 \%$ apresentaram no máximo Educação Básica completa, enquanto apenas $13,2 \%$ possuíam ou estavam cursando Ensino Médio ou Superior), e considerou-se que os resultados encontrados no estudo, foram maiores níveis educacionais do que os encontrados por Ney \& Hoffmann (2009) e semelhantes aos obtidos por Neves et al. (2011).

Observou-se ainda que o grau de instrução não diferiu ( $\mathrm{P}>0,05$ no teste $\chi 2)$ entre as regiões estudadas, sendo o nível educacional semelhante ao encontrado por ICEPA (2011), no Estado de Santa Catarina. Os aspectos encontrados na pesquisa, como baixa escolaridade e idade dos produtores acima de 40 anos, podem influenciar a aceitação de novas tecnologias de produção e a dificuldade de adaptação às formas de produção que comprovadamente melhoram a quantidade e qualidade do leite produzido (ARCURI et al, 2006; NERO et al., 2009).

$\mathrm{Na}$ maioria das propriedades $(55,4 \%)$ residiam de 4 a 7 pessoas, que utilizavam em média 170 horas-homem/mês para a atividade leite, $o$ que perfazia aproximadamente 6 horas diárias de serviço. Ressalte-se que $91,6 \%$ não contratavam mão de obra externa.

Apenas $64,5 \%$ dos produtores declararam que recebiam algum tipo de assistência técnica. Desses, $83,8 \%$ afirmaram que eram assistidos pela empresa para a qual 
comercializavam o leite, e $31,4 \%$ eram assistidos por órgãos governamentais. Deve-se frisar que esse resultado é melhor do que os encontrados por Neves et al. (2011) e Marcondes (2005) em estudos realizados em Pernambuco e Santa Catarina, respectivamente, quando considerado o grau de percepção sobre a assistência técnica recebida pelos produtores.

A proporção de produtores que entendiam receber algum tipo de assistência técnica, não diferiu $(\mathrm{P}>0,05$ no teste $\chi 2)$ em função da área e quantidade de leite produzida. Destaca-se o elevado percentual de produtores que afirmaram não receber assistência técnica (34,5\%), ao considerar que a pecuária leiteira é uma atividade complexa, que requer acompanhamento técnico para a produção de leite de qualidade e com rendimento compatível.

A área média e desvio-padrão das propriedades pesquisadas eram de $30,2 \pm 29,3$ ha (variando de 3 a 216ha), não diferiam entre as regiões $(\mathrm{P}>0,05$ no teste $\left.\chi^{2}\right)$ e, aproximadamente $70 \%$, apresentavam menos de 30 hectares. A área média correspondia a aproximadamente dois módulos rurais. A maioria dos produtores pesquisados desenvolvia mais de uma atividade na propriedade, dos quais apenas $18,1 \%$ produziam somente leite, em uma área média de 24,3ha. Esses resultados foram semelhantes aos encontrados por ICEPA (2011) e demonstram a pluriatividade agrícola presente nas propriedades do Estado de Santa Catarina.

O número médio e desvio-padrão de bovinos de leite por propriedade foi $22,7 \pm 13,3$ animais (variando de 4 a 99), sendo que propriedades com até 20 animais representaram $52,5 \%$ do total, classificadas segundo ICEPA (2011) como pequenas propriedades, e apenas $6,5 \%$ das propriedades possuíam mais de 40 animais (Tabela 1 ).

Tabela 1. Frequência de propriedades de acordo com o número de bovinos de leite

\begin{tabular}{lccc}
\hline Item & Número de animais & Número de propriedades & Frequência (\%) \\
\hline \multirow{4}{*}{ Bovinos de leite } & Até 10 & 24 & 14,5 \\
& 11 a 20 & 63 & 38,0 \\
& 21 a 30 & 47 & 28,3 \\
& 31 a 40 & 21 & 12,7 \\
& Mais de 40 & 11 & 6,5 \\
\hline \multirow{4}{*}{ Vacas em lactação } & Até 5 & 32 & 19,3 \\
& 6 a 10 & 74 & 44,6 \\
& 11 a 20 & 50 & 30,1 \\
& 21 a 30 & 08 & 4,8 \\
& Mais de 31 & 02 & 1,2 \\
\hline
\end{tabular}

Em média, os rebanhos possuíam 9,1 $\pm 8,4$ bezerras e novilhas ( $40,2 \%$ do rebanho) e $13,6 \pm 13,3$ vacas $(59,8 \%$ do rebanho), das quais $9,4 \pm 7,9$ encontravam-se em lactação $(69,3 \%)$, percentual abaixo do recomendado.

O tamanho do rebanho foi similar nas duas regiões estudadas. Entretanto, a raça predominante diferiu entre as 
regiões $(\mathrm{P}<0,01$ no teste $\chi 2)$. Enquanto na região do Meio-oeste, em 58,3\% das propriedades predominava a raça Holandesa, no Alto vale do Itajaí, em $58,2 \%$ das propriedades predominou a Jersey. As raças especializadas, especialmente a Holandesa, predominaram nos rebanhos maiores, enquanto animais sem raça definida estavam presentes somente em pequenas propriedades (Tabela 2).

Tabela 2. Número e proporção de propriedades de acordo com a raça predominante em cada faixa de produção de leite diária

\begin{tabular}{lrrccc}
\hline \multirow{2}{*}{ Produção (1/dia) } & \multicolumn{3}{c}{ Propriedades } & \multicolumn{3}{c}{ Percentagem por faixa de produção (\%) } \\
\cline { 2 - 6 } & Número & \multicolumn{1}{c}{$\%$} & Holandês & Jersey & SRD $^{1}$ \\
\hline Até 50 & 103 & 64,0 & 29,1 & 44,7 & 26,2 \\
51 a 100 & 43 & 26,7 & 69,8 & 23,2 & 7,0 \\
101 a 200 & 10 & 6,2 & 70,0 & 30,0 & 0,0 \\
Mais de 200 & 5 & 3,1 & 80,0 & 20,0 & 0,0 \\
\hline
\end{tabular}

${ }^{1}$ Sem raça definida.

O volume médio de leite comercializado

e o desvio-padrão foi $97,6 \pm 107,2$ litros/propriedade/dia (variação de 14 a1000 litros), com predomínio de pequenas propriedades. As propriedades com menos de 100 litros/dia perfaziam aproximadamente $90 \%$ das propriedades (Tabela 2).

A produção média nos meses de menor e maior produção foi $78,5 \pm 132,5$ e $144,7 \pm 207,6$ litros dias, respectivamente, o que representou um incremento de $84 \%$ no mês de maior produção em relação ao mês de menor produção. Isso acarreta dificuldades de obtenção de regularidade de renda e, segundo Ney \& Hoffmann (2009), a sazonalidade da renda na agricultura é um dos pontos que mais impactam negativamente sob o ponto de vista econômico. Por exemplo, no mês de menor produção, $45,8 \%$ das propriedades produziram menos de 50 litros, o que determinou um rendimento muito baixo para a família rural.

Em 49,4\% das entrevistas, os produtores declararam que o leite é a principal atividade econômica da propriedade e a segunda atividade, em $38,6 \%$ das propriedades, sem diferença entre as regiões ou tamanho de propriedade $(\mathrm{P}>0,05$ no teste $\chi 2)$. Ficou evidente a importância da pecuária leiteira para as propriedades fornecedoras de leite aos laticínios estudados, ao considerar que em $88,0 \%$ das propriedades o leite representou uma das duas principais atividades geradoras de renda.

Apesar de o estudo envolver duas regiões de Santa Catarina distantes, aproximadamente $200 \mathrm{~km}$ entre si, com relevo, clima, colonização e matriz produtivas diferentes, para os produtores de leite, em ambos os locais, essa atividade tem importância econômica similar dentro das propriedades (ICEPA, 2011). Além da atividade leite, as demais atividades de destaque, como primeiras atividades econômicas foram, na Região do Meio-Oeste, a suinocultura, presente em 19,0\%, a avicultura em $14,3 \%$ e a cultura do milho em $4,8 \%$ das propriedades, enquanto no Alto Vale do Itajaí $32,9 \%$ das propriedades atuavam em fumicultura e 7,6\% em cebolicultura. A ordenha manual ainda era utilizada em 
$33,7 \%$ das propriedades, principalmente nas pequenas, as quais produziam em média 42 litros/dia, enquanto produtores com ordenha mecânica produziam cerca de três vezes mais (125 litros). Esses dados demonstram que quanto maior a produção de leite, maior a capacidade de investimento em equipamentos, assim como a maior produção implicava na necessidade deste.

As propriedades tinham como locais de ordenha o estábulo convencional (94\%), enquanto apenas $6 \%$ das propriedades possuíam sala de ordenha com fosso. Nas propriedades com ordenha mecânica, o sistema de balde ao pé representava $96,4 \%$ e o sistema canalizado apenas $3,6 \%$.

Segundo Winck \& Thaler Neto (2009), em pesquisa realizada nas mesmas regiões deste estudo, o fato de o produtor possuir ordenha mecânica, em comparação com aqueles que possuíam ordenha manual, não impactou significativamente na melhoria da qualidade do leite $(\mathrm{P}>0,05$ pelo teste de Tukey). Esse resultado, segundo os autores, pode ser explicado pela deficiência de higiene e manejo correto do equipamento de ordenha, inclusive impactando negativamente na qualidade, ou seja, produtores com ordenha mecânica tinham na média, resultados piores do que os de ordenha manual.

O resfriamento do leite após a ordenha ainda era realizado utilizando freezer ou refrigerador em 19,2\% das propriedades, que apresentavam reduzida produção de leite (Tabela 3). Esses equipamentos dificultam a diminuição da temperatura em curto espaço de tempo, o que pode dificultar a manutenção da qualidade do leite.

Tabela 3. Produção diária de leite de acordo com o método de resfriamento após a ordenha

\begin{tabular}{lccc}
\hline Método de resfriamento & $\begin{array}{c}\text { Número de } \\
\text { propriedades }\end{array}$ & Frequência (\%) & $\begin{array}{c}\text { Produção média } \\
\text { de leite }(1)\end{array}$ \\
\hline Tanque de expansão & 40 & 24,2 & $155,8^{\mathrm{a}}$ \\
Tanque de imersão & 94 & 56,6 & $93,1^{\mathrm{b}}$ \\
Freezer/Refrigerador & 32 & 19,2 & $39,7^{\mathrm{c}}$ \\
\hline
\end{tabular}

Médias seguidas de mesma letra não diferem entre si $(\mathrm{P}>0,05)$ pelo Teste de Tukey.

A utilização de resfriador por expansão direta, crescente em ambas as regiões, de acordo com dados da pesquisa, poderia estar relacionada à preocupação dos produtores em melhorar o resfriamento do leite de forma homogênea, bem como ao incentivo das indústrias ao pagarem um adicional para produtores que possuíam este equipamento.

A frequência da utilização dos diferentes métodos de resfriamento não diferiu entre as regiões $\left(\mathrm{P}>0,05\right.$ no teste $\left.\chi^{2}\right)$, porém diferiu de acordo com o nível de produção diária de leite, $(\mathrm{P}<0,01$ no teste $\chi^{2}$ ) (Tabela 2). Aparentemente, os produtores com baixo volume de produção não investiam em equipamentos de resfriamento por não possuírem renda suficiente para adquiri-los e devido ao elevado custo fixo de energia elétrica por litro de leite armazenado, problema esse que poderia ser minimizado pela utilização de tanques comunitários, que podem diluir os custos entre os produtores. 
A falta de equipamentos de refrigeração adequados dificulta a manutenção da qualidade microbiológica do produto e pode comprometer toda a produção diária (ARCURI et al., 2006). Consequentemente, esses produtores poderiam ter maior dificuldade para atingir as metas estabelecidas pela Instrução Normativa 51 (BRASIL, 2002). Salienta-se, entretanto, que a aquisição de sistemas mais avançados de refrigeração de leite, em curso especialmente em propriedades leiteiras médias e grandes, por si só, não garante a obtenção de níveis elevados de qualidade do leite, uma vez que o resfriamento não melhora a qualidade do produto, simplesmente a preserva.

Além dos equipamentos de ordenha e refrigeração, outros equipamentos $\mathrm{e}$ máquinas frequentemente disponíveis nas propriedades eram cerca elétrica $(90,4 \%)$, trator $(48,8 \%)$, microtrator $(33,7 \%)$, ensiladeira $(50,6 \%)$ e semeadora (47,6\%).

A normatização de qualidade do leite (IN 51) não era conhecida adequadamente pelos produtores. Ao serem questionados se conheciam ou já "tinham ouvido falar" da normatização de qualidade do leite brasileira, 38,6\% declararam que nunca "tinham ouvido falar", 32,5\% já "tinham ouvido falar", mas não conheciam, 26,5\% conheciam um pouco e apenas $2,4 \%$ afirmaram dominar o conhecimento.

Esses dados são preocupantes, visto que, a normatização está em vigor desde 2002 e menos de $30 \%$ produtores a conheciam, o que torna difícil a melhoria da qualidade, ao se considerar que os produtores não conheciam as metas a serem atingidas e não dominavam o assunto. Dentre os produtores que afirmavam conhecer a normativa, as fontes de informação mais comuns foram palestras dos laticínios $(24,7 \%)$, rádio e televisão $(20,5 \%)$ e informações de técnicos da empresa (10,8\%).

Quanto à expectativa de impacto da IN 51 em suas propriedades, dentre os que souberam responder, a maioria considerou que o impacto seria alto (Tabela 4), o que não estava relacionado ao nível de produção de leite das propriedades.

Tabela 4. Opinião dos produtores sobre o impacto da IN 51 na propriedade leiteira e produção diária de leite

\begin{tabular}{lccc}
\hline Impacto da IN 51 & $\begin{array}{c}\text { Número de } \\
\text { produtores }\end{array}$ & Frequência (\%) & $\begin{array}{c}\text { Produção média de } \\
\text { leite }(\mathrm{kg} / \text { dia })\end{array}$ \\
\hline Nenhum ou Baixo & 15 & 23,1 & $129,7^{\mathrm{a}}$ \\
Médio & 14 & 21,5 & $129,6^{\mathrm{a}}$ \\
Alto & 36 & 55,4 & $109,9^{\mathrm{a}}$ \\
\hline
\end{tabular}

Médias seguidas da mesma letra não diferem estatisticamente $(\mathrm{P}>0,05)$ pelo Teste de Tukey.

Questionou-se os produtores sobre o que precisariam mudar para adequaremse à IN 51, dando a eles a possibilidade de citar mais de um fator. Muitos apontaram que precisavam melhorar em mais de um ponto; já 63,9\% não conseguiram responder a essa questão, pelo desconhecimento da normativa. Dentre os que responderam, observou-se que a percepção sobre as necessidades para se adequar à IN 51, está fortemente centrada na aquisição de equipamentos (Erro! Fonte de referência não encontrada.), com menor ênfase na 
melhoria da higiene de ordenha e no controle da mastite.

Sobre a possibilidade do cumprimento das exigências da normativa vir a afetar a remuneração do leite comercializado, $37,8 \%$ dos produtores acreditavam que sim e 45,5\% que não, enquanto os demais não tinham opinião formada.

Quando questionados sobre o recebimento de algum tipo de incentivo financeiro relacionado à qualidade do leite, não houve diferença significativa entre os produtores das duas regiões
( $\mathrm{P}>0,05$ no teste $\chi 2)$. Metade deles $(48,2 \%)$ tinha percepção de receber algum tipo de incentivo. Como critério de qualidade, somente o teor de gordura do leite foi citado, além do volume de leite comercializado e da existência de equipamentos, mais especificamente, tanque de expansão. Existiu relação entre a percepção do produtor que recebia algum incentivo financeiro e a produção diária de leite do mesmo $(\mathrm{P}<0,05$ no teste $\chi 2)$.

Tabela 5. Opinião dos produtores sobre mudanças necessárias para adequação à IN 51

\begin{tabular}{lcc}
\hline Adequação à IN 51 & Número de propriedades & Frequência (\%) \\
\hline Mudar o sistema de ordenha & 25 & 41,7 \\
Adquirir equipamentos & 38 & 63,3 \\
Melhorar a higiene & 16 & 26,7 \\
Controlar a mastite & 08 & 13,3 \\
Não precisa melhorar nada & 05 & 8,3 \\
Outras & 05 & 8,3 \\
\hline
\end{tabular}

Os produtores com maior volume de leite entregue tinham a percepção de recebem financeiramente maiores bonificações pelo volume de leite comercializado e também por consequência, por possuírem tanques de expansão, o que é corrente com os critérios de bonificação adotados pelas indústrias de laticínios, as quais não possuíam programa de remuneração pela qualidade oficialmente implantado.

Observa-se pelos resultados que os produtores de leite ainda não estavam preparados para se adequar às exigências de qualidade vigentes no país, especialmente, devido à falta de informações e o consequente enfoque exagerado em equipamentos $\mathrm{e}$ instalações, com menor preocupação na melhoria da obtenção higiênica do leite. Conclui-se que a produção de leite nas regiões pesquisadas baseia-se na agricultura familiar, praticada por produtores com baixa escolaridade e idade elevada, os quais criam predominantemente animais das raças Holandesa e Jersey, utilizam ordenha mecânica e resfriadores de imersão, tendo na produção de leite uma das suas principais fontes de renda. Para a melhoria da qualidade do leite nas regiões pesquisadas, recomenda-se maior ênfase na capacitação dos produtores, visto que em sua grande maioria, os produtores não apresentam conhecimento adequado sobre a IN 51. Nesse sentido, os produtores envolvidos nesta pesquisa entendiam ser necessário adquirir equipamentos e melhorar instalações, contrastando com reduzida preocupação na melhoria da obtenção higiênica do leite e na saúde da glândula mamária. 
Rev. Bras. Saúde Prod. Anim., Salvador, v.13, n.2, p.296-305 abr./jun., 2012 http://www.rbspa.ufba.br ISSN 15199940

\section{REFERÊNCIAS}

ARCURI, E.F.; BRITO, M.A.V.P.; BRITO, J.R.F.; PINTO, S.M.; ANGELO, F.F.; SOUZA, G.N . Qualidade microbiológica do leite refrigerado nas fazendas. Arquivo Brasileiro de Medicina Veterinária e Zootecnia, v.58, p.440-446, 2006.

BODENMÜLLER FILHO, A.; DAMASCENO, J.C.R; PREVIDELLI, I.T.S.; SANTANA, R.G.; RAMOS, C.E.C.O.; SANTOS, G.T. Tipologia de sistemas de produção baseada nas características do leite. Revista Brasileira de Zootecnia, v.39, n.8, p.1832-1839, 2010.

BRASIL. Ministério da Agricultura, Pecuária e Abastecimento. Instrução Normativa $n^{\circ} .51$, de 20 de setembro de 2002. Aprova os regulamentos técnicos de produção, identidade, qualidade, coleta e transporte de leite. Diário Oficial da União, Brasília, DF, 20 set. 2002. Seção 1, p.13-22.

FIGUEIREDO, J.C.; PAULILLO, L.F. Gênese, modernização e reestruturação do complexo agroindustrial lácteo brasileiro.

Revista Organizações Rurais Agroindustriais, v.7, n.2, p.173-187, 2006.

HAGUETTE, T.M. Metodologias qualitativas na sociologia. Petrópolis: Vozes, 1990. 245p.

INSTITUTO DE PLANEJAMENTO E ECONOMIA AGRÍCOLA DE SANTA CATARINA - ICEPA. Centro de Socioeconomia e Planejamento Agrícola Epagri/Cepa. Síntese Anual da Agricultura de Santa Catarina 20092010. 2011. Disponível em: $<$ http://cepa.epagri.sc.gov.br/Publicacoes/ Sintese_2010/sintese\%202010_inteira.pdf $>$ Acesso em 03 de maio de $20 \overline{1} 1$.
MARCONDES, T. Produção leiteira em Santa Catarina: situação atual e perspectivas. Agropecuária catarinense, v. 18, n.1, p.20-23, 2005.

NERO, L.A.; VIÇOSA, G.N.; PEREIRA, F.E.V. Qualidade microbiológica do leite determinada por características de produção. Ciência e Tecnologia Alimentar, v.29, n.2, p.386-390, 2009.

NEVES, A.L.A.; PEREIRA, L.G.R.; SANTOS, R.D.; ARAÚJO, G.G.L.; CARNEIRO, A.V.; MORAES, S.A.; SPANIOL, C.M.O.; ARAGÃO, A.S.L. Caracterização dos produtores e dos sistemas de produção de leite no perímetro irrigado de Petrolina/PE. Revista Brasileira de Saúde e Produção Animal [Online], v.12, n.1, p.209-223, 2011.

NEY, M.G. HOFFMANN, R. Educação, concentração fundiária e desigualdade de rendimentos no meio rural brasileiro. Revista de Economia e Sociologia Rural, v.47, n.1, p.147-181, 2009.

ROMA JÚNIOR, L.C.; MONTOYA, J.F.G.; CASSOLI, L.D. MACHADO, P.F. Sazonalidade do teor de proteína e outros componentes do leite e sua relação com programa de pagamento por qualidade. Arquivo Brasileiro de Medicina Veterinária e Zootecnia, v.61, n.6, p.1411-1418, 2009.

SIQUEIRA, K.B.; KILMER, R.L. CAMPOS, A.C. The dynamics of farm milk price formation in Brazil. Revista de Economia e Sociologia Rural, v.48, n. 1, p.41-61, 2010.

THIOLLENT, M. Metodologia da pesquisa-ação. São Paulo: Cortez, 1996. 108p. 
Rev. Bras. Saúde Prod. Anim., Salvador, v.13, n.2, p.296-305 abr./jun., 2012 http://www.rbspa.ufba.br ISSN 15199940

WINCK, C.A.; THALER NETO, A.

Diagnóstico da adequação de

propriedades leiteiras em Santa Catarina

às normas brasileiras de qualidade do

leite. Revista de Ciências

Agroveterinárias, v.8, n.2, p.164-172, 2009.
ZOCCAL, R. Ranking da Produção de Leite por Estado, 2008/2010. 2011. Disponível em:

$<$ http://www.cnpgl.embrapa.br/nova/inf ormacoes/estatisticas/producao/tabela02 40.php> Acesso em: 8 sete. 2011.

Data de recebimento: 18/07/2011

Data de aprovação: 26/01/2012 